\title{
Moving Toward a Consensus DSC-MRI Protocol: Validation of a Low-Flip Angle Single-Dose Option as a Reference Standard for Brain Tumors
}

\author{
(D).M. Schmainda, (D) M.A. Prah, (D).S. Hu, (D)C.C. Quarles, (D) N. Semmineh, (D) S.D. Rand, (D).M. Connelly, (D)B. Anderies, (D)Y. Zhou, \\ (D) Y. Liu, (D) B. Logan, (D)A. Stokes, (D) G. Baird, and (D).L. Boxerman
}

\begin{abstract}
BACKGROUND AND PURPOSE: DSC-MR imaging using preload, intermediate $\left(60^{\circ}\right)$ flip angle and postprocessing leakage correction has gained traction as a standard methodology. Simulations suggest that DSC-MR imaging with flip angle $=30^{\circ}$ and no preload yields relative CBV practically equivalent to the reference standard. This study tested this hypothesis in vivo.

MATERIALS AND METHODS: Eighty-four patients with brain lesions were enrolled in this 3-institution study. Forty-three patients satisfied the inclusion criteria. DSC-MR imaging (3T, single-dose gadobutrol, gradient recalled-echo-EPI, TE $=20-35 \mathrm{~ms}, \mathrm{TR}=1.2-1.63 \mathrm{~seconds}$ ) was performed twice for each patient, with flip angle $=30^{\circ}-35^{\circ}$ and no preload $(P-)$, which provided preload $(P+)$ for the subsequent intermediate flip angle $=60^{\circ}$. Normalized relative $\mathrm{CBV}$ and standardized relative $\mathrm{CBV}$ maps were generated, including postprocessing with contrast agent leakage correction $(\mathrm{C}+$ ) and without $(\mathrm{C}-$ ) contrast agent leakage correction. Contrast-enhancing lesion volume, mean relative $\mathrm{CBV}$, and contrast-to-noise ratio obtained with $30 \% \mathrm{P}-/ \mathrm{C}-, 30 \% \mathrm{P}-/ \mathrm{C}+$, and $60^{\circ} / \mathrm{P}+/ \mathrm{C}-$ were compared with $60 \% \mathrm{P}+/ \mathrm{C}+$ using the Lin concordance correlation coefficient and Bland-Altman analysis. Equivalence between the $30 \% / \mathrm{P}-/ \mathrm{C}+$ and $60 \% \mathrm{P}+/ \mathrm{C}+$ protocols and the temporal SNR for the $30 \% \mathrm{P}-$ and $60 \% \mathrm{P}+$ DSC-MR imaging data was also determined.
\end{abstract}

RESULTS: Compared with $60^{\circ} / \mathrm{P}+/ \mathrm{C}+, 30^{\circ} / \mathrm{P}-/ \mathrm{C}+$ had closest mean standardized relative CBV $(P=.61)$, highest Lin concordance correlation coefficient (0.96), and lowest Bland-Altman bias $(\mu=1.89)$, compared with 30\% $/ P-/ C-(P=.02$, Lin concordance correlation coefficient $=0.59$, $\mu=14.6)$ and $60^{\circ} \mathrm{P}+/ \mathrm{C}-(P=.03$, Lin concordance correlation coefficient $=0.88, \mu=-10.1)$ with no statistical difference in contrast-to-noise ratios across protocols. The normalized relative $\mathrm{CBV}$ and standardized relative $\mathrm{CBV}$ were statistically equivalent at the $10 \%$ level using either the $30 \% \mathrm{P}-/ \mathrm{C}+$ or $60^{\circ} / \mathrm{P}+/ \mathrm{C}+$ protocols. Temporal SNR was not significantly different for $30 \% \mathrm{P}-$ and $60 \% \mathrm{P}+(\mathrm{P}=.06)$.

CONCLUSIONS: Tumor relative CBV derived from low-flip angle, no-preload DSC-MR imaging with leakage correction is an attractive single-dose alternative to the higher dose reference standard.

ABBREVIATIONS: $\mathrm{C}-=$ postprocessing without contrast agent leakage correction; $\mathrm{C}+=$ postprocessing with contrast agent leakage correction; $\mathrm{LCCC}=\mathrm{Lin}$ concordance correlation coefficient; $\mathrm{nRCBV}=$ normalized relative $\mathrm{CBV} ; \mathrm{P}-=$ a preload of contrast agent was not administered; $\mathrm{P}+=$ a preload of contrast agent was administered; $r C B V=$ relative $C B V ;$ sRCBV = standardized relative CBV

D SC-MR imaging measurement of relative cerebral blood volume (rCBV) is the most commonly used approach for brain tumor perfusion imaging, with numerous studies demonstrating its value to predict glioma grade, overall survival, and response to

Received November 13, 2018; accepted after revision January 18, 2019

From the Departments of Biophysics (K.M.S., M.A.P.), Radiology (K.M.S., S.D.R.), Neurology (J.M.C.), and Division of Biostatistics, Institute for Health and Society (Y.L., B.L.). Medical College of Wisconsin, Milwaukee, Wisconsin; Departments of Radiology (L.S.H., Y.Z.) and Neurosurgery (B.A.), Mayo Clinic, Scottsdale, Arizona; Division of Imaging Research (C.C.Q., N.S., A.S.), Barrow Neurological Institute, Phoenix, Arizona; and Department of Diagnostic Imaging (J.L.B., G.B.), Rhode Island Hospital and Warren Alpert Medical School of Brown University, Providence, Rhode Island.

This work was supported by National Institutes of Health/National Cancer Institute: $\mathrm{U} 01$ CA176110 (K.M.S., M.A.P., S.D.R., J.M.C.), R01 CA 082500 (K.M.S., M.A.P., S.D.R., J.M.C.), U01 CA180820 (J.L.B., G.B.), R01 CA158079 (C.C.Q.), R01 CA221938 (K.M.S., C.C.Q., L.S.H., J.L.B.), R01 CA213158 (A.S.), ADHS16-162414 (A.S.), R01 CA213158 (N.S.), and U01 CA220378 (L.S.H.). treatment. ${ }^{1-8}$ Yet, widespread adoption of DSC-MR imaging for clinical trials and daily practice has been impeded by lack of agreement on the best data collection and analysis methodology, including the choice of the preload dose to mitigate the effects of contrast agent extravasation, bolus contrast-agent dose, flip angle, $\mathrm{TE}$, and the use of postprocessing leakage correction. In response,

Paper previously presented, in part, at: International Society of Magnetic Resonance in Medicine Annual Meeting and Exhibition and 35th Annual Scientific Meeting of the Congress of European Society of Magnetic Resonance in Medicine and Biology, June 16-22, 2018, Paris, France; and Annual Meeting of the American Society of Neuroradiology and the Foundation of the ASNR Symposium, June 2-7, 2018, Vancouver, British Columbia, Canada.

Please address correspondence to Kathleen M. Schmainda, PhD, Medical College of Wisconsin, Department of Biophysics, 8701 W Watertown Plank Rd, Milwaukee, WI 53226; e-mail: kathleen@mcw.edu

- Indicates open access to non-subscribers at www.ajnr.org

http://dx.doi.org/10.3174/ajnr.A6015 


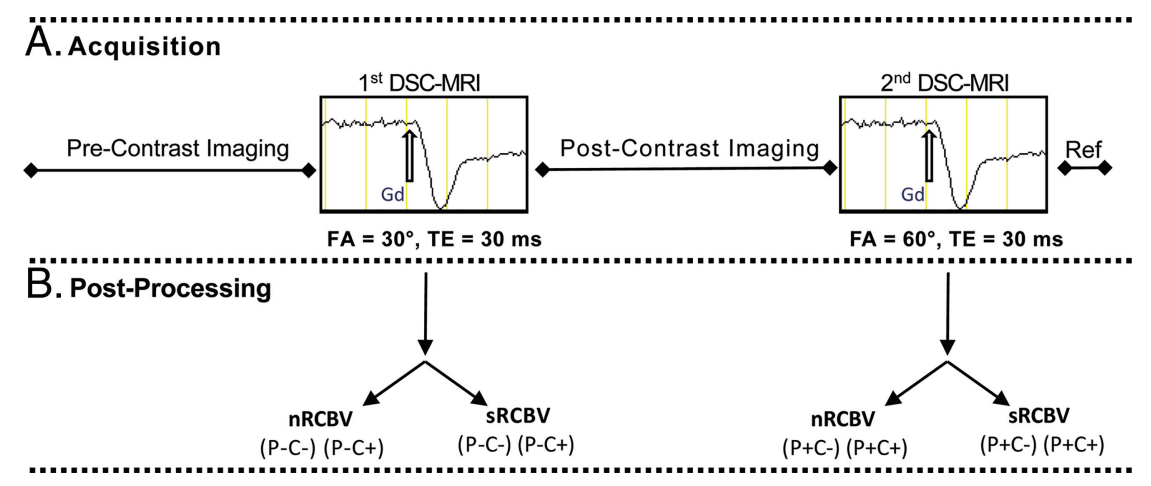

FIG 1. Acquisition protocol with postprocessing options. A, After precontrast standard imaging is performed, a standard dose of gadolinium contrast $(0.1 \mathrm{mmol} / \mathrm{kg})$ is administered during which DSC-MR imaging data are collected using gradient recalled-echo-EPI with a flip angle (FA) of $30^{\circ}$ and $\mathrm{TE}=30 \mathrm{~ms}$. This first contrast agent injection serves as the preload $(\mathrm{P}+)$ for the second DSC-MR imaging acquisition. Next, postcontrast anatomic images are collected, followed by the second DSC-MR imaging acquisition during which a second dose of gadolinium contrast $(0.1$ $\mathrm{mmol} / \mathrm{kg}$ ) is administered. Finally, an anatomic reference (Ref) scan is obtained using a slice prescription that exactly matches the DSC-MR imaging slice prescription. $B$, Given the order of the data collection, 8 different $\mathrm{rCBV}$ maps can be created for each subject that include both normalized and standardized rCBV for each of these 4 conditions: 1) $30^{\circ} / \mathrm{P}-/ \mathrm{C}-$, 2) $30^{\circ} / \mathrm{P}-/ \mathrm{C}+$, 3) $60 \% \mathrm{P}+/ \mathrm{C}-$, and 4) $60^{\circ} / \mathrm{P}+/ \mathrm{C}+$.

a study was performed to compare the most commonly published approaches for the determination of brain tumor $\mathrm{rCBV}^{9}$; the results were that for single-echo methodologies, the approach using full-dose contrast agent preload and postprocessing leakage correction proved best. This result was confirmed by several subsequent studies, ${ }^{1,2,10-12}$ including a recent multicenter study showing excellent concordance across sites for the analysis of DSC-MR imaging data acquired with a full-dose preload and bolus. ${ }^{13}$

Continued effort toward harmonization includes a recent American Society of Functional Neuroradiology white paper recommending a $60^{\circ}-70^{\circ}$ flip angle, field-strength-dependent TE, and one-fourth-to-full-dose preload with a full-dose bolus. ${ }^{14}$ Yet a more recent constraint is that DSC-MR imaging paradigms comply with the standardized brain tumor imaging protocol, ${ }^{15}$ requiring postcontrast imaging to be performed after 1 full dose of gadolinium-based contrast agent, either split between the preload and DSC-MR imaging bolus before postcontrast imaging or given fully as a preload with variable-bolus-dose DSC-MR imaging after postcontrast imaging.

To further assist effort toward DSC-MR imaging harmonization, two independent studies using sophisticated computer simulations were recently performed, ${ }^{16,17}$ one of which used a glioblastoma-trained digital reference object permitting an exhaustive search of many possible combinations of acquisition parameters under a range of simulated physiologic conditions. ${ }^{17}$ This search revealed that the American Society of Functional Neuroradiology parameters with flip angle $=60^{\circ}$ and TE $=30 \mathrm{~ms}$ had excellent accuracy and precision at both $1.5 \mathrm{~T}$ and $3 \mathrm{~T}$ for single-dose preload and bolus, but substantially degraded performance for fractional dosing schemes, and especially poor performance without preload. However, DSC-MR imaging without preload but with a comparatively lower flip angle $\left(30^{\circ}\right)$ and a midrange TE (30 ms at 3T) performed nearly as well as the double-dosing scheme, but also very well for fractional dosing schemes and even without using any preload dose.

While this theory is promising, data are lacking to support it.
Therefore, this study aimed to confirm these simulation results in vivo and to determine whether single-dose, low-flip angle DSC-MR imaging without preload gives rCBV estimates practically equivalent to double-dose, intermediateflip angle DSC-MR imaging with fulldose preload and bolus in patients with contrast-enhancing brain lesions, including gliomas. Adoption of this protocol would eliminate preload contrast agent injection and reduce contrast agent usage.

\section{MATERIALS AND METHODS Patients}

All participants provided written, informed consent according to institutional review board policy in this Health Insurance Portability and Accountability Act-compliant study. Patients diagnosed with a brain tumor or vascular malformation who were scheduled for a clinically indicated DSC-MR imaging were considered for inclusion in this 3-institution (Medical College of Wisconsin, Rhode Island Hospital, Mayo Clinic Arizona) prospective study. The lesion was required to be at least $1 \mathrm{~mL}$, and the DSC-MR imaging data had to be of sufficient quality with a discernable signal transient without large motion artifacts to ensure a robust comparison between DSC methods as applied to lesion tissue only.

\section{Imaging}

All studies were performed on 3T MR imaging systems (MAGNETOM Skyra (Siemens, Erlangen, Germany), MAGNETOM Verio (Siemens, Erlangen, Germany), PET/MR (GE Healthcare, Milwaukee, Wisconsin) and two Discovery 750W systems (GE Healthcare, Milwaukee, Wisconsin). Figure $1 A$ depicts the imageacquisition protocol. Following standard precontrast FLAIR and T1-weighted spin-echo imaging, we performed low-flip angle $\left(30^{\circ}\right)$ DSC-MR imaging (gradient recalled-echo EPI, TE/TR = $20-35 \mathrm{~ms} / 1200-1630 \mathrm{~ms}$ ) without contrast agent preload (P-) using a bolus injection of $0.1 \mathrm{mmol} / \mathrm{kg}$ of gadobutrol (Gadavist; Bayer Schering Pharma, Berlin, Germany). Additional DSC-MR imaging scan parameters included the following: $\mathrm{FOV}=220 \mathrm{~mm}$, matrix $=96 \times 96$ or $128 \times 128$, slice thickness $=4-5 \mathrm{~mm}$, skip $=$ $0 \mathrm{~mm}$. Subsequently postcontrast T1-weighted images were obtained according to the clinical protocol of each site, and a second DSC-MR imaging was performed using an intermediate flip angle $\left(60^{\circ}\right)$ and otherwise identical acquisition parameters. The time between the first and second DSC-MR imaging study was 5-8 minutes. By virtue of the acquisition order, the second DSC-MR imaging was performed with a contrast agent preload $(\mathrm{P}+)$ provided by the first DSC-MR imaging bolus. For both DSC-MR imaging datasets, 120 time points were collected and gadobutrol was bolus-injected ( $3-5 \mathrm{~mL} / \mathrm{s})$ after $40-60$ baseline images. When the DSC-MR slices were not an exact subset of the T1-weighted image slices, an additional T1-weighted "reference" scan was ob- 
tained using a slice prescription (orientation and spacing) matching the DSC-MR imaging examination for ease of coregistering the DSC-MR images to the anatomic images.

\section{Image Analysis}

All imaging data were anonymized and postprocessed at a central site (Medical College of Wisconsin) using OsiriX Imaging Software (http:// www.osirix-viewer.com) with IB Neuro ${ }^{\mathrm{TM}}$ and IB Delta Suite ${ }^{\mathrm{TM}}$ plugins (Imaging Biometrics, Elm Grove, Wiscon$\sin$ ). Both normalized (nRCBV) to normal-appearing white matter (NAWM) and standardized (sRCBV) ${ }^{18}$ maps were created. The NAWM ROI, selected by 1 person (M.A.P.), comprised two 8-mm-diameter circular ROIs placed on 2 separate image slices at the midventricular level within the normal brain near the frontal horns of the lateral ventricles. When this area was abnormal, the ROIs were drawn near the occipital horns. Standardization is a unique machine-learned calibration rule ${ }^{19}$ that yields quantitative rCBV maps with consistent values across time and patients. ${ }^{20}$ Unlike nRCBV, the creation of sRCBV does not require the determination of a reference ROI.

Both nRCBV and sRCBV maps were created for DSC-MR imaging datasets obtained without $(\mathrm{C}-)$ and with $(\mathrm{C}+)$ application of Boxerman-Schmainda-Weisskoff leakage correction previously described in detail ${ }^{10}$ and implemented in a vendor-specific fashion by IB Neuro ${ }^{\mathrm{TM}}$. Therefore, 8 different rCBV maps were created for each subject, including nRCBV and sRCBV for each of 4 conditions: $30 \% / \mathrm{P}-/ \mathrm{C}-, 30 \% \mathrm{P}-/ \mathrm{C}+, 60 \% \mathrm{P}+/ \mathrm{C}-$, and $60 \% / \mathrm{P}+\mathrm{C}+$.

Using the IB Delta Suite ${ }^{\mathrm{TM}}$, we defined contrast-enhancing lesion volumes from quantitative dT1 (delta T1) maps, computed from the difference between calibrated and registered post- and precontrast T1-weighted images. ${ }^{21}$ The quantitative dT1 maps facilitate visualization of the enhancing lesion, free of intrinsically increased T1 signal from blood products or proteinaceous material. Because dT1 maps are quantitative, a single threshold can be applied to all cases for consistent delineation of contrast-enhancing lesion volume. The DSC-MR imaging volume was likewise coregistered to the contrast-enhanced T1-weighted images via the reference scan. The contrast-enhancing lesion volume ROI was transferred to the rCBV maps from which the rCBV mean and standard error of the mean could be determined using the ROI analysis tools available within OsiriX.

\section{Statistical Analysis}

Because subjects were their own control, mean estimates were modeled using generalized mixed modeling with sandwich estimation, assuming normal and log-normal distributions, in which observations were nested within each patient using SAS/GLIMMIX (SAS Institute Inc., Cary, North Carolina). Because residuals were heterogeneous (differences increased with increasing contrast-enhancing lesion volume), a log-normal distribution was also used. As a conservative effort, the Dunnett method was used for multiple comparisons, where $\mathrm{P}+/ \mathrm{C}+$ was the control to examine whether the alternative approaches deviated significantly. Moreover, a Bonferroni correction was also used, where the $P$ value was adjusted for 6 comparisons, 0.05/6 $=0.00833$.

The Lin concordance correlation coefficients (LCCCs) and
Bland-Altman plots were calculated across all subjects for nRCBV and sRCBV obtained with $30 \% \mathrm{P}-/ \mathrm{C}-, 30 \% \mathrm{P}-/ \mathrm{C}+$, and $60 \%$ $\mathrm{P}+/ \mathrm{C}-$ protocols relative to the reference standard $\left(60^{\circ} / \mathrm{P}+/\right.$ $\mathrm{C}+$ ). Unlike intraclass or Pearson correlation coefficients, the LCCC provides a measure of both accuracy (deviation from the line of equality) and precision (deviation from best-fit line) rather than precision alone.

For methods showing strong agreement with the reference standard, a statistical equivalence test was performed. An equivalence test begins with the null hypothesis that the two tests are not equivalent, but if the $95 \% \mathrm{CI}$ is contained in the margin, then the null is rejected and equivalence is confirmed for the chosen margins.

The contrast-to-noise ratio was also calculated across all subjects for nRCBV and sRCBV obtained with $30^{\circ} / \mathrm{P}-/ \mathrm{C}-, 30^{\circ} / \mathrm{P}-1$ $\mathrm{C}+$, and $60^{\circ} / \mathrm{P}+/ \mathrm{C}-$ protocols relative to the reference standard $\left(60^{\circ} / \mathrm{P}+/ \mathrm{C}+\right)$, as follows:

$$
C N R=\left[\mu_{\mathrm{x}}-\mu_{\mathrm{y}}\right] /\left[\sigma_{\mathrm{x}}^{2}+\sigma_{\mathrm{y}}^{2}\right]^{1 / 2},
$$

where $\mu$ and $\sigma$ are the mean and SD of the ROI and $\mathrm{x}$ and $\mathrm{y}$ designate tumor and white matter, respectively. As a final comparison of acquisition methods, the temporal signal-to-noise ratio $(t S N R)$ was determined as follows:

$$
t S N R=\left[\mu_{\mathrm{BL}}-\delta_{\mathrm{BL}}\right] / \sigma_{\mathrm{BL}},
$$

where $\mu, \sigma$, and $\delta$ are the mean, $\mathrm{SD}$, and minimum of the baseline (BL) signal time points used for the rCBV calculations. The paired Student $t$ test was used to compare the mean contrast-to-noise ratio with the reference standard and tSNR between the $30^{\circ}$ and $60^{\circ}$ acquisitions.

\section{RESULTS}

Since January 2017, eighty-four subjects from 3 institutions have been enrolled in this study. Of these, 41 were excluded from analysis because of contrast-enhancing lesion volume $<1 \mathrm{~mL}(n=35)$ or the DSC-MR imaging image quality being insufficient for analysis $(n=6)$. The diagnoses for the remaining patients $(n=43)$ were grade IV glioblastoma $(n=29)$ and fibrillary and gemistocytic astrocytoma $(n=1)$; grade III anaplastic astrocytoma ( $n=$ 4 ) and anaplastic oligodendroglioma $(n=1)$; high-grade glioma with treatment effect $(n=1)$; grade II oligodendroglioma $(n=1)$ and astrocytoma with treatment effect $(n=1)$; grade II atypical meningioma $(n=1)$; cavernous malformation $(n=1)$; and metastases $(n=3)$.

Sample images and parameter maps for a patient with glioblastoma are shown in Fig 2. The sRCBV maps are qualitatively similar for the $30^{\circ} / \mathrm{P}-/ \mathrm{C}+($ Fig $2 D)$ and $60^{\circ} / \mathrm{P}+/ \mathrm{C}+$ protocols (Fig $2 F)$.

The results from all analyses are listed in Tables $1-3$ and plotted in Figs 3-5. Table 1 gives the rCBV statistics for each of the 8 acquisition/postprocessing protocols and the $P$ value indicating whether the mean $\mathrm{rCBV}$ is significantly different from the $60 \%$ $\mathrm{P}+/ \mathrm{C}+$ reference. The mean $\mathrm{rCBV}$ data are shown in Fig 3 for both nRCBV (Fig $3 A$ ) and sRCBV (Fig 3B). The sRCBV using the $30^{\circ} \mathrm{P}-\mathrm{C}+$ protocol was not significantly different from the reference $(P=.61)$, while the nRCBV was borderline different $(P=$ $.06)$. 
There was excellent/substantial agreement ${ }^{22,23}$ between the $30 \% \mathrm{P}-/ \mathrm{C}+$ protocol and the reference standard $(60 \% \mathrm{P}+/ \mathrm{C}+)$, with LCCC values of 0.952 and 0.960 for nRCBV and sRCBV, respectively (Table 2). The nRCBV and sRCBV LCCC values were

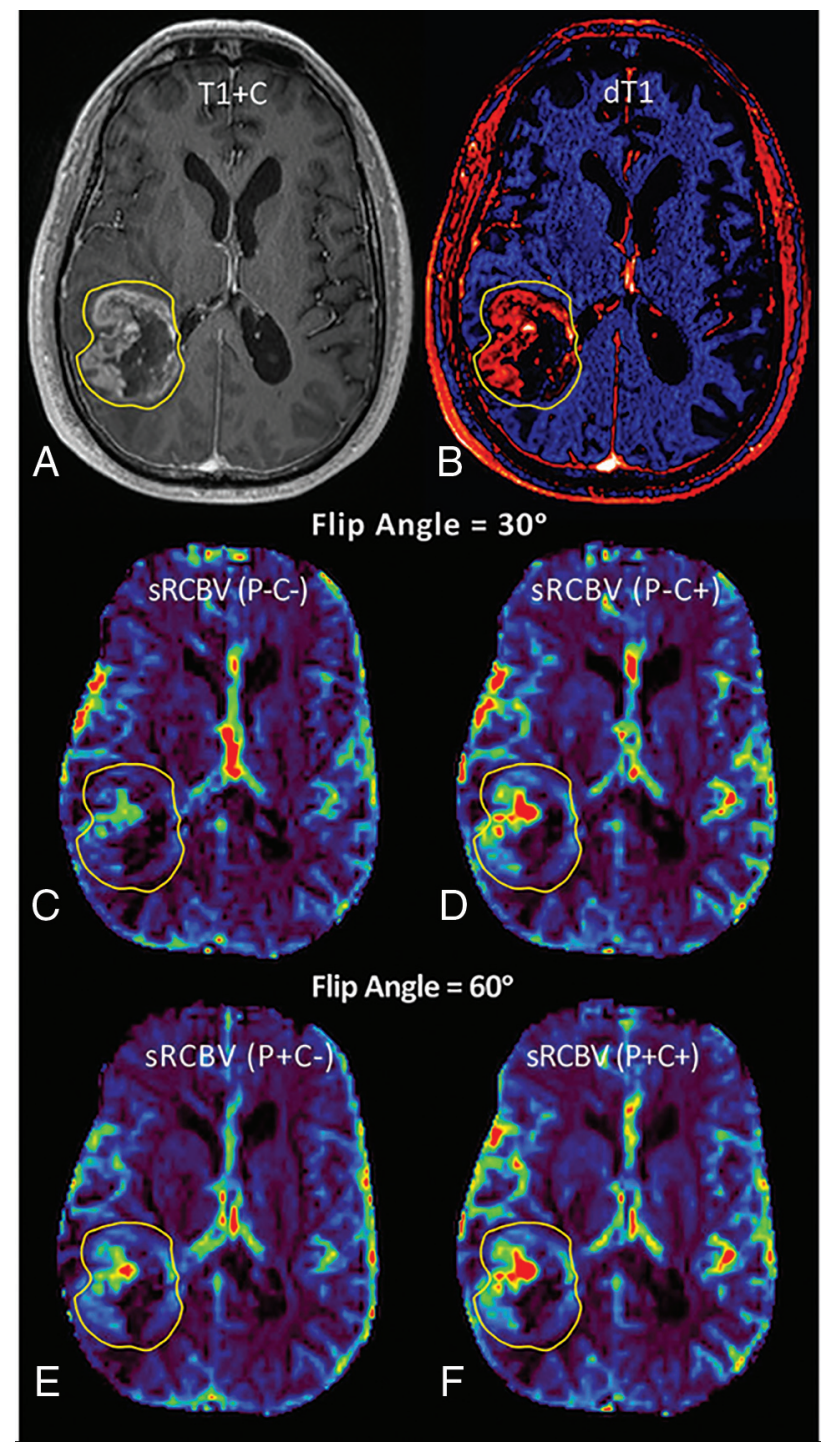

FIG 2. Images and sRCBV parameter maps from a patient with glioblastoma. Shown are the post-contrast Tl-weighted $(T 1+C)(A)$ and quantitative $\mathrm{dT}(B)$ images with the corresponding sRCBV maps obtained from the first DSC-MR imaging contrast dose $(C$ and $D)$ without preload $(\mathrm{P}-)$ and without leakage correction $(\mathrm{C}-)$ and without preload $(\mathrm{P}-)$ plus leakage correction $(\mathrm{C}+)$. The sRCBVs obtained during the second contrast dose $(E$ and $F)$ and thus after the preload are shown without $(\mathrm{P}+\mathrm{C}-)$ and with $(\mathrm{P}+\mathrm{C}+)$ leakage correction.

Table 1: Mean rCBV in reference to flip angle $=60^{\circ} / \mathrm{P}+/ \mathrm{C}+$

\begin{tabular}{lcccc}
\hline Parameter/Metric & $\mathbf{3 0 ^ { \circ }}(\mathbf{P}-\mathrm{C}-)$ & $\mathbf{3 0 ^ { \circ }}(\mathbf{P}-\mathrm{C}+)$ & $\mathbf{6 0 ^ { \circ }}(\mathbf{P}+\mathrm{C}-)$ & $\mathbf{6 0 ^ { \circ }}(\mathbf{P}+\mathrm{C}+)$ \\
\hline nRCBV & & & & \\
Mean & $1.42 \pm 0.79$ & $1.67 \pm 0.93$ & $2.01 \pm 1.06$ & $1.77 \pm 1.03$ \\
$95 \% \mathrm{Cl}$ & $1.18-1.66$ & $1.39-1.96$ & $1.68-2.34$ & $1.46-2.09$ \\
$P$ value & .003 & $.06^{\mathrm{a}}$ & .002 & $\mathrm{NA}$ \\
$\mathrm{sRCBV}$ & & & & \\
Mean & $1.17 \pm 0.55$ & $1.34 \pm 0.68$ & $1.48 \pm 0.64$ & $1.37 \pm 0.73$ \\
$95 \% \mathrm{Cl}$ & $1.0-1.34$ & $1.13-1.55$ & $1.28-1.68$ & $1.15-1.60$ \\
$P$ value & .05 & $.61^{\mathrm{a}}$ & .07 & $\mathrm{NA}$ \\
\hline
\end{tabular}

Note:-NA indicates not applicable.

a Significant. much lower for the $30^{\circ} / \mathrm{P}-/ \mathrm{C}-(0.648,0.588)$ and $60^{\circ} / \mathrm{P}+/ \mathrm{C}-$ $(0.884,0.877)$ protocols. These results are depicted in Fig 4 , with a Deming regression line and the identity line for reference. There was substantial improvement in the concordance provided by postprocessing leakage correction based on the sizable increase in LCCC between $30 \% / \mathrm{P}-/ \mathrm{C}-$ and $30 \% \mathrm{P}-/ \mathrm{C}+$ for both nRCBV and sRCBV. Likewise, the Bland-Altman plots (Fig 5) and associated bias values (Table 3 ) demonstrate that $30^{\circ} / \mathrm{P}-/ \mathrm{C}+$ yielded substantially improved limits of agreement with minimal bias ( $\mu=1.89$ ) compared with $30^{\circ} / \mathrm{P}-/ \mathrm{C}-$ and $60^{\circ} / \mathrm{P}+/ \mathrm{C}-$ protocols (14.64 and -10.13 , respectively) for sRCBV, with similar results for nRCBV.

Equivalence of the 2 measurements $\left(30^{\circ} / \mathrm{P}-/ \mathrm{C}+\right.$ versus $60 \%$ $\mathrm{P}+/ \mathrm{C}+)$ was determined for a $\pm 10 \%$ change at a significance level of .01. For nRCBV and sRCBV, the difference of measurements $\left(30^{\circ} / \mathrm{P}-/ \mathrm{C}+\right.$ versus $\left.60^{\circ} / \mathrm{P}+/ \mathrm{C}+\right)$ in the log scale was $-0.0517 \pm 0.132$ and $-0.0191 \pm 0.136$, respectively. The $95 \%$ CIs for percentage change for $30 \% \mathrm{P}-/ \mathrm{C}+$ compared with $60 \%$ $\mathrm{P}+/ \mathrm{C}+$ were $(-9.12 \%$ to,$-1.11 \%)$ for $\mathrm{nRCBV}$ and $(-5.92 \%$, $-2.31 \%)$ for sRCBV. The $P$ values of rejecting the 1 -sided null hypothesis ( $\mathrm{H} 0: 30^{\circ} / \mathrm{P}-/ \mathrm{C}+<90 \%$ of $60^{\circ} / \mathrm{P}+/ \mathrm{C}+$ ) were .00531 for $\mathrm{nRCBV}$ and .0000782 for $\mathrm{sRCBV}$, indicating equivalence between the methods.

For all protocols, there was no statistically significant difference between the tumor-to-white matter contrast-to-noise ratio with respect to the reference. The temporal SNR of the DSC-MR imaging signal was not significantly different between the $30 \% \mathrm{P}-$ and $60^{\circ} \mathrm{P}+$ acquisitions for white matter $(P=.35)$, trended toward significance for tumor $(P=.06)$, and was significantly different for gray matter $(P=.008)$ with mean temporal SNRs of 2.11 and 2.22 for the $30 \% \mathrm{P}-/ \mathrm{C}+$ and $60 \% \mathrm{P}+/ \mathrm{C}+$ conditions, respectively.

\section{DISCUSSION}

This study confirms the theoretic conjecture of recent simulations ${ }^{16,17,24}$ and demonstrates in vivo that low-flip angle, nopreload DSC-MR imaging has excellent/substantial concordance $^{22,23}$ with full-dose preload-based, intermediate-flip angle DSC-MR imaging and should be considered for consensus protocol recommendation. It uses less contrast agent and requires fewer contrast agent injections, eliminating the potential error due to variable preload dosing and timing schemes. However, postprocessing leakage correction is impactful and essential, even for low-flip angle acquisitions with less T1-weighting.

Historically, a higher flip angle $\left(90^{\circ}\right)$ was commonly used for DSC-MR imaging. This was largely motivated by early studies using spin-echo ${ }^{25-27}$ or combined spinecho plus gradient-echo ${ }^{1,2,28}$ EPI sequences, in which a higher flip angle preserved the SNR. Alternative gradientecho approaches using a lower flip angle $\left(30^{\circ}-35^{\circ}\right)$ diminished $\mathrm{T} 1$ contamination effects due to contrast agent extravasation; however, longer TEs (ie, $54 \mathrm{~ms}$ ) were typically chosen to maintain $\mathrm{T}^{*}$ sensitivity to the susceptibility effect induced by the passage of contrast agent 
Table 2: Lin concordance correlation coefficient (LCCC) and Deming equations

\begin{tabular}{|c|c|c|c|c|c|c|}
\hline & \multicolumn{3}{|c|}{$\mathrm{nRCBV}$} & \multicolumn{3}{|c|}{ sRCBV } \\
\hline & $\mathrm{LCCC}$ & Slope CI & Equation (Deming) & LCCC & Slope CI & Equation (Deming) \\
\hline $\mathrm{P}-\mathrm{C}-$ & 0.648 & $(0.48-0.90)$ & $y=0.69 \times x+0.19$ & 0.588 & $(0.41-0.90)$ & $y=0.65 \times x+0.27$ \\
\hline $\mathrm{P}-\mathrm{C}+$ & 0.952 & (0.82-0.98) & $y=0.90 \times x+0.07$ & 0.960 & (0.85-1.01) & $y=0.93 \times x+0.07$ \\
\hline $\mathrm{P}+\mathrm{C}-$ & 0.884 & (0.88-1.19) & $y=1.04 \times x+0.17$ & 0.877 & $(0.73-0.99)$ & $y=0.86 \times x+0.30$ \\
\hline
\end{tabular}

Table 3: Bland-Altman results

\begin{tabular}{|c|c|c|c|c|c|c|}
\hline \multirow[b]{2}{*}{ Metric } & \multicolumn{3}{|c|}{ nRCBV } & \multicolumn{3}{|c|}{ sRCBV } \\
\hline & P-C- & P-C+ & $P+C-$ & P-C- & P-C+ & $\mathrm{P}+\mathrm{C}-$ \\
\hline Bias & 21.34 & 5.14 & -12.48 & 14.64 & 1.89 & -10.13 \\
\hline $95 \% \mathrm{Cl}$ & $(9.9-32.8)$ & (1.1-9.2) & $(-5.8$ to -19.2$)$ & $(2.8-26.4)$ & $(-2.3-6.1)$ & $(-3.7$ to -16.6$)$ \\
\hline SD bias & 37.29 & 13.08 & 21.85 & 38.35 & 13.56 & 20.86 \\
\hline Lower LOA & -51.75 & -20.49 & -55.31 & -60.52 & -24.68 & -51.01 \\
\hline Upper LOA & 94.43 & 30.78 & 30.34 & 89.79 & 28.46 & 30.75 \\
\hline
\end{tabular}

Note:-Bias indicates the mean of the percentage difference; LOA, limits of agreement $=$ bias $\pm 1.96 \times$ SD of bias.

Mean nRCBV

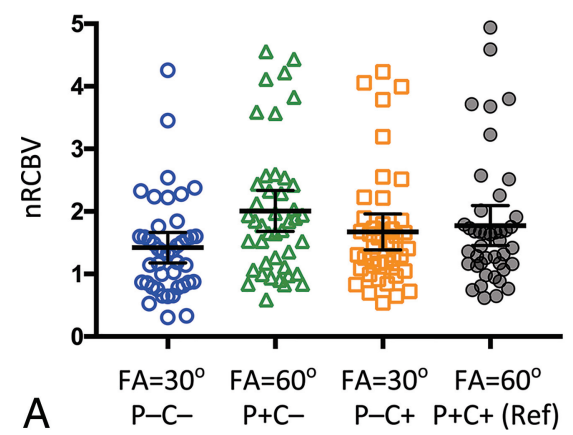

Mean sRCBV

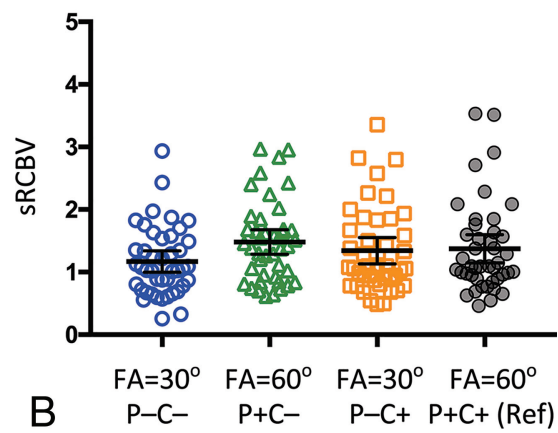

FIG 3. Normalized and standardized mean $r C B V$ results. Mean $n R C B V(A)$ and $s R C B V(B)$ for each of the acquisition/postprocessing conditions without/with preload $(\mathrm{P}-/ \mathrm{P}+)$ and without and with leakage correction $(\mathrm{C}-\mathrm{C}+$ ).

bolus. ${ }^{29,30}$ Comparative rCBV data from brain tumors indicated that low-flip angle, long-TE approaches were suboptimal for distinguishing high-grade tumor from normal-appearing brain ${ }^{9}$ and often required manual identification of rCBV "hot spots" to obtain clinically relevant results. Instead, preload-based DSC-MR imaging using intermediate-to-high flip angles with a minimum TE and postprocessing leakage correction was found to work best. ${ }^{9}$ Yet a systematic exploration of the image-acquisitionparameter space aimed at maximizing the DSC-MR imaging signal while minimizing contrast agent leakage effects had not been performed until recently. We considered $60 \% \mathrm{P}+/ \mathrm{C}+$ to be the reference standard because its utility, ${ }^{1,2}$ reliability, ${ }^{20}$ and accuracy $^{9,12}$ have been repeatedly proved in multiple treatment and outcomes studies, ${ }^{4-6,31}$ including those with spatially correlated tissue samples ${ }^{8,11,32}$ and recent simulations as described above. ${ }^{16,17,24}$

For this study, the $\pm 10 \%$ difference chosen for the test of equivalence is clinically justified because clinically relevant $\mathrm{rCBV}$ changes of $>10 \%$ have been frequently reported. For example, it was shown that for patients treated with topotecan, the percentage change in $\mathrm{rCBV}$ at 1 month for those with progressive disease was $+12 \%$ versus $-29 \%$ for those with nonprogressive disease $(P=.02) .{ }^{33}$ Similarly, after treatment with radiation-temozolomide, patients with pseudoprogression had a mean decrease in rCBV of $41 \%$ and those with true progression had a mean increase in rCBV of $12 \% .{ }^{34}$ In addition, in a multicenter clinical trial, ${ }^{5}$ all patients with a statistically significant survival advantage had a mean decrease in $\mathrm{rCBV}$ of $53 \%$ measured at 2 weeks after starting treatment with bevacizumab. Finally, another indication that the $10 \%$ margin is indicative of excellent agreement is the previously reported repeatability of the intermediate-flip angle technique (repeatability coefficient $=1.78),{ }^{20}$ measured twice within a few days, which is worse than the estimated agreement in this study between the leakage-corrected low-flip angle and intermediate-flip angle techniques (repeatability coefficient $=0.59$ ).

The ability to obtain comparable rCBV measurements with up to $50 \%$ less contrast agent is a step toward addressing concerns regarding the use of suprastandard $(>0.1 \mathrm{mmol} / \mathrm{kg})$ contrast agent dosing. This is important due to recent restrictions imposed by the FDA on the use of gadoliniumbased contrast agents due to the small-but-real risk of nephrogenic systemic fibrosis ${ }^{35}$ and more recent concerns regarding gadolinium deposition in the brain. ${ }^{36}$ Single-dose, low-flip angle methodology also improves the likelihood of performing DSC-MR imaging more routinely on both adult and pediatric patients because it would require no extra contrast agent beyond standard dosing for conventional T1-weighted postcontrast imaging and could be acquired during the standard bolus injection of contrast agent.

In addition to reducing the contrast agent dose, the low-flip angle, no-preload protocol eliminates the potential for variability in measured rCBV resulting from variations in contrast agent incubation time. $\mathrm{Hu}$ et $\mathrm{al}^{11}$ demonstrated that with an incubation time of 5-6 minutes between a single or half-dose preload and bolus injection, rCBV could distinguish posttreatment-related enhancement from recurrent tumor. However, other than simulations showing little dependence of rCBV on incubation time, ${ }^{16,17,24}$ there are no other in vivo data addressing the potential influence of incubation time on rCBV measurements. By not using any preload, the low-flip angle protocol eliminates the chance that measured $\mathrm{rCBV}$ fluctuations due 
nRCBV

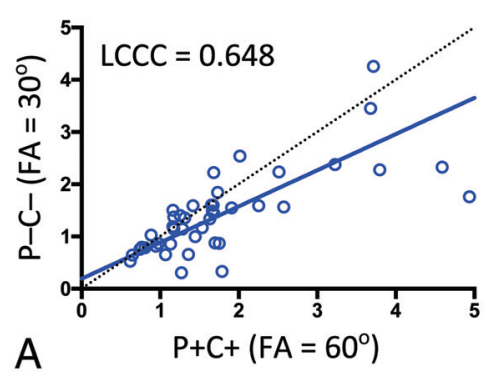

$$
\text { A }
$$

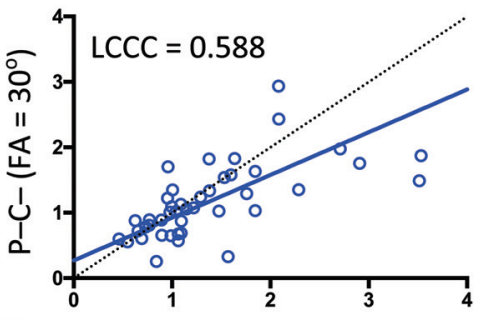

D
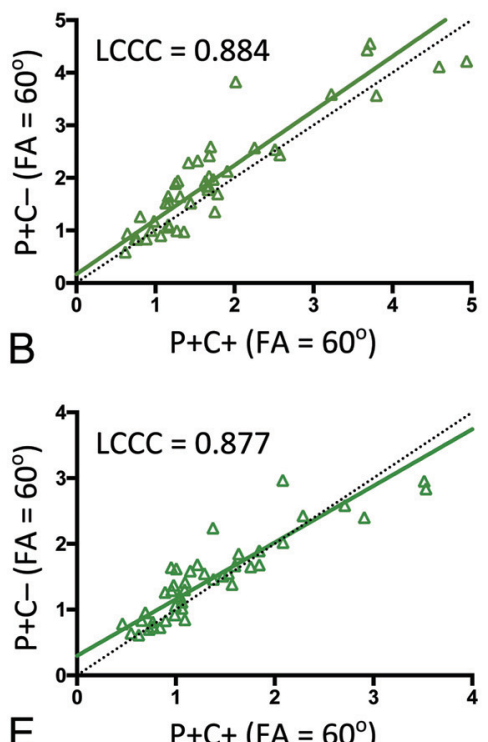
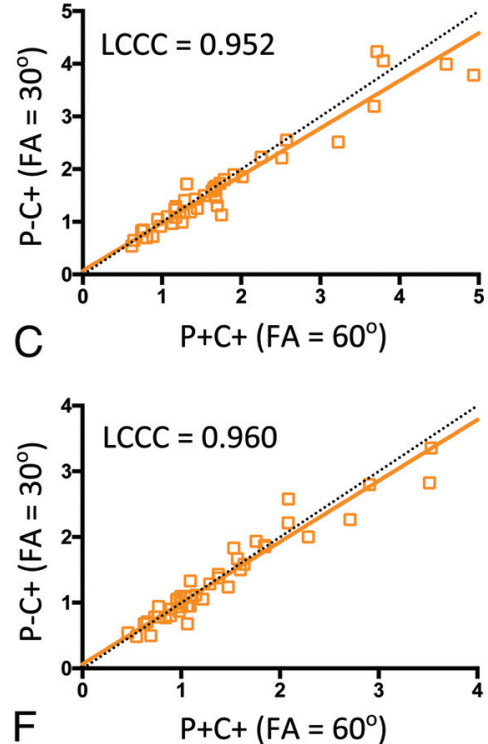

FIG 4. The Lin concordance correlation (LCCC) results, including Deming regression (solid lines), for normalized rCBV $(A-C)$ and standardized $\operatorname{rCBV}(D-F)$ for each of the preload $(\mathrm{P})$ and leakage-correction $(C)$ conditions in reference to the $60^{\circ} / \mathrm{P}+/ \mathrm{C}+\mathrm{condition}$. The $30^{\circ} / \mathrm{P}-/ \mathrm{C}+$ condition for both nRCBV $(C)$ and SRCBV $(F)$ has the best concordance. FA indicates flip angle.

\section{$30 \%$ P-/C -}

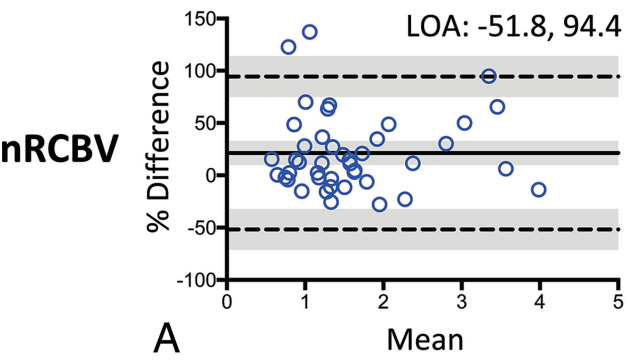

A

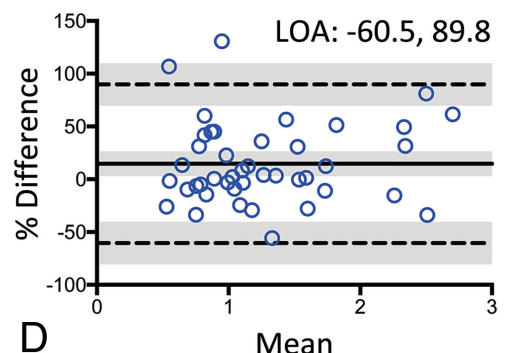

$60^{\circ} / \mathrm{P}+/ \mathrm{C}-$
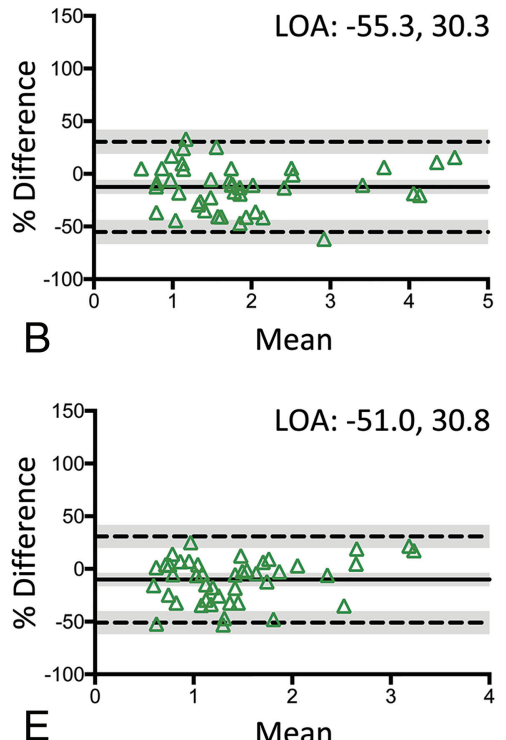

$30^{\circ} / \mathrm{P}-/ \mathrm{C}+$
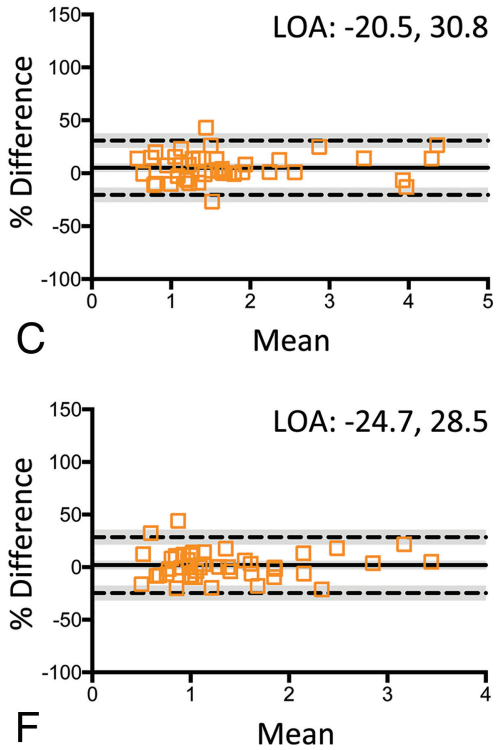

FIG 5. Bland-Altman results for normalized $\mathrm{rCBV}(A-C)$ and standardized $\mathrm{rCBV}(D-F)$ for each of the preload $(\mathrm{P})$ and leakage-correction $(C)$ conditions in comparison with the $60^{\circ} / \mathrm{P}+/ \mathrm{C}+$ reference standard. The $30^{\circ} / \mathrm{P}-/ \mathrm{C}+$ protocol for both nRCBV $(C)$ and sRCBV $(F)$ shows the best limits of agreement with minimal bias.

to inadvertent differences in incubation time could be mistaken for true differences in tumor rCBV.

The complete elimination of the preload dose would be an important advancement for efforts to harmonize DSC-MR imaging acquisitions. Balancing the experimentally proven benefit of preload with the goal of maintaining total contrast dose near single-dose levels $(0.1 \mathrm{mmol} / \mathrm{kg})$ has resulted in several disparate dosing protocols. While many studies have reported clinically relevant results using a single-dose preload, ${ }^{9,11}$ others have used fractional preload doses consistent with the American Society of Functional Neuroradiology recommendation ${ }^{14}$ but unproven experimentally. Additionally, in an effort to comply with the contrast agent dosing and timing required for the consensus brain tumor imaging protocol, ${ }^{15}$ some have chosen to split the single dose between the preload and bolus dose, again without experimental evidence to justify this choice. Given the recent simulation results, ${ }^{16,17,24}$ there is concern that split-dose protocols will yield suboptimal rCBV estimations, potentially impacting decisions re- 
garding the efficacy of clinical trials and the utility of $\mathrm{rCBV}$ as a treatment-response biomarker. Therefore, this study motivates adoption of a single-dose, no-preload protocol that would overcome current limitations regarding harmonization of DSC-MR imaging acquisition and dosing protocols.

Although several previous studies collected DSC-MR imaging data using a lower flip angle, ${ }^{29,30,37-39}$ these studies also used a longer TE of approximately $50 \mathrm{~ms}$ in an effort to accentuate $\mathrm{T} 2{ }^{*}$ weighting. This combination of a low flip angle with intermediate-long TEs may explain why earlier low-flip angle approaches proved less reliable compared with other higher flip angle techniques, ${ }^{9}$ which provided clinically relevant results only when tumor hot spots were sampled. ${ }^{39}$ Simulations have also demonstrated that the combination of a lower flip angle with a longer TE at $3 \mathrm{~T}$ is less accurate and reliable. ${ }^{17}$

The temporal SNR was reduced in gray matter for the lower flip angle method, with a statistically significant difference in comparison with the $60 \% \mathrm{P}+/ \mathrm{C}+$ method. Although no differences were found for white matter and tumor, a reduced SNR must be considered when balancing the benefits of using less contrast agent with a reduced SNR when using lower flip angle methods.

Additional limitations of this study include a small number of patients and therefore necessitate performing a larger multicenter trial in which a greater range of tumor types and grades are studied. Also, as the simulations predict, low-flip angle methods may be less reliable compared with the preload/higher flip angle methods at $1.5 \mathrm{~T}$. Therefore, repeating this study at $1.5 \mathrm{~T}$ is necessary to confirm the $30 \% \mathrm{P}-/ \mathrm{C}+$ method as a general replacement for the reference standard $60 \% \mathrm{P}+/ \mathrm{C}+$. Although statistical tests indicate excellent agreement, further evaluation of the repeatability of these methods and their ability to predict clinical outcomes are required. Finally, the results of this study were obtained using a single postprocessing platform. Thus, equivalent results obtained with other platforms cannot be guaranteed solely on the basis of the results reported here.

\section{CONCLUSIONS}

This study provides experimental evidence showing that rCBV can be reliably determined using a single dose of contrast agent and a low-flip angle, no-preload acquisition at 3T.

\section{ACKNOWLEDGMENTS}

We thank Cathy Marszalkowski, Radiology Research Coordinator, who has played a key role in the recruitment of patients with brain tumor at the Medical College of Wisconsin, and the Robert C. Olson MD Endowment for providing support for Dr Kathleen Schmainda.

Disclosures: Kathleen M. Schmainda-RELATED: Grant: National Institutes of Health/National Cancer Institute, Comments: U01 and R01 grants*; UNRELATED: Grants/Grants Pending: National Institutes of Health, Comments: several grants pending*; Stock/Stock Options: IQ-Al, Comments: ownership interest; Other: IQ-Al, Comments: spouse's salary. Leland S. Hu-RELATED: Grant: National Institutes of Health, Comments: U01 CA220378, R01 CA221938.* Christopher C. QuarlesRELATED: Grant: National Institutes of Health. * ${ }^{*}$ Money paid to the institution.

\section{REFERENCES}

1. Donahue KM, Krouwer HGJ, Rand SD, et al. Utility of simultaneously acquired gradient-echo and spin-echo cerebral blood volume and morphology maps in brain tumor patients. Magn Reson Med 2000;43:845-53 CrossRef Medline

2. Schmainda KM, Rand SD, Joseph AM, et al. Characterization of a first-pass gradient-echo spin-echo method to predict brain tumor grade and angiogenesis. AJNR Am J Neuroradiol 2004;25:1524-32 Medline

3. Kong DS, Kim ST, Kim EH, et al. Diagnostic dilemma of pseudoprogression in the treatment of newly diagnosed glioblastomas: the role of assessing relative cerebral blood flow volume and oxygen-6methylguanine-DNA methyltransferase promoter methylation status. AJNR Am J Neuroradiol 2011;32:382-87 CrossRef Medline

4. Schmainda KM, Prah M, Connelly J, et al. Dynamic-susceptibility contrast agent MRI measures of relative cerebral blood volume predict response to bevacizumab in recurrent high-grade glioma. Neuro Oncol 2014;16:880-88 CrossRef Medline

5. Schmainda KM, Zhang Z, Prah M, et al. Dynamic susceptibility contrast MRI measures of relative cerebral blood volume as a prognostic marker for overall survival in recurrent glioblastoma: results from the ACRIN 6677/RTOG 0625 multicenter trial. Neuro Oncol 2015;17:1148-56 CrossRef Medline

6. Kickingereder P, Wiestler B, Burth S, et al. Relative cerebral blood volume is a potential predictive imaging biomarker of bevacizumab efficacy in recurrent glioblastoma. Neuro Oncol 2015;17: 1139-47 CrossRef Medline

7. Hu LS, Eschbacher JM, Heiserman JE, et al. Reevaluating the imaging definition of tumor progression: perfusion MRI quantifies recurrent glioblastoma tumor fraction, pseudoprogression, and radiation necrosis to predict survival. Neuro Oncol 2012;14:919-30 CrossRef Medline

8. Prah MA, Al-Gizawiy MM, Mueller WM, et al. Spatial discrimination of glioblastoma and treatment effect with histologically-validated perfusion and diffusion magnetic resonance imaging metrics. J Neurooncol 2018;136:13-21 CrossRef Medline

9. Paulson ES, Schmainda KM. Comparison of dynamic susceptibilityweighted contrast-enhanced MR methods: recommendations for measuring relative cerebral blood volume in brain tumors. Radiology 2008;249:601-13 CrossRef Medline

10. Boxerman JL, Schmainda KM, Weisskoff RM. Relative cerebral blood volume maps corrected for contrast agent extravasation significantly correlate with glioma tumor grade, whereas uncorrected maps do not. AJNR Am J Neuroradiol 2006;27:859-67 Medline

11. Hu LS, Baxter LC, Pinnaduwage DS, et al. Optimized preload leakage-correction methods to improve the diagnostic accuracy of dynamic susceptibility-weighted contrast-enhanced perfusion MR imaging in posttreatment gliomas. AJNR Am J Neuroradiol 2010;31: 40-48 CrossRef Medline

12. Boxerman JL, Prah DE, Paulson ES, et al. The role of preload and leakage correction in gadolinium-based cerebral blood volume estimation determined by comparison with MION as a criterion standard. AJNR Am J Neuroradiol 2012;33:1081-87 CrossRef Medline

13. Schmainda KM, Prah MA, Rand SD, et al. Multisite concordance of DSC-MRI analysis for brain tumors: results of a National Cancer Institute Quantitative Imaging Network Collaborative Project. AJNR Am J Neuroradiol 2018;39:1008-16 CrossRef Medline

14. Boxerman JL, Shiroishi MS, Ellingson BM, et al. Dynamic susceptibility contrast MR imaging in glioma: review of current clinical practice. Magn Reson Imaging Clin N Am 2016;24:649-70 CrossRef Medline

15. Ellingson BM, Bendszus M, Boxerman J, et al; Jumpstarting Brain Tumor Drug Development Coalition Imaging Standardization Steering Committee. Consensus recommendations for a standardized brain tumor imaging protocol in clinical trials. Neuro Oncol 2015; 17:1188-98 CrossRef Medline

16. Leu K, Boxerman JL, Ellingson BM. Effects of MRI protocol parameters, preload injection dose, fractionation strategies, and leakage 
correction algorithms on the fidelity of dynamic-susceptibility contrast MRI estimates of relative cerebral blood volume in gliomas. AJNR Am J Neuroradiol 2017;38:478-84 CrossRef Medline

17. Semmineh NB, Bell LC, Stokes AM, et al. Optimization of acquisition and analysis methods for clinical dynamic susceptibility contrast MRI using a population-based digital reference object. AJNR Am J Neuroradiol 2018;39:1981-88 CrossRef Medline

18. Bedekar D, Jensen TR, Schmainda KM. Standardization of relative cerebral blood volume (rCBV) image maps for ease of both interand intrapatient comparisons. Magn Reson Med 2010;64:907-13 CrossRef Medline

19. Nyúl LG, Udupa JK. On standardizing the MR image intensity scale. Magn Reson Med 1999;42:1072-81 CrossRef Medline

20. Prah MA, Stufflebeam SM, Paulson ES, et al. Repeatability of standardized and normalized relative $\mathrm{CBV}$ in patients with newly diagnosed glioblastoma. AJNR Am J Neuroradiol 2015;36:1654-61 CrossRef Medline

21. Bedekar D, Jensen T, Rand S, et al. Delta T1 Method: an automatic post-contrast RO1 selection technique for brain tumors. In: Proceedings of the International Society for Magnetic Resonance in Medicine, Stockholm, Sweden. May 1-7, 2010

22. Altman DG. Practical Statistics for Medical Research. London: Chapman and Hall/CRC Texts in Statistical Science Series, Taylor \& Francis; 1990

23. McBride GB. A proposal for strength-of-agreeement criteria for Lin's concordance correlation coefficient. NIWA Client Report: HAM2005-062 2005:62

24. Semmineh NB, Stokes AM, Bell LC, et al. A population-based digital reference object (DRO) for optimizing dynamic susceptibility contrast (DSC)-MRI methods for clinical trials. Tomography 2017;3: 41-49 CrossRef Medline

25. Oh J, Henry RG, Pirzkall A, et al. Survival analysis in patients with glioblastoma multiforme: predictive value of choline-to- $\mathrm{N}$-acetylaspartate index, apparent diffusion coefficient, and relative cerebral blood volume. J Magn Reson Imaging 2004;19:546-54 CrossRef Medline

26. Lev MH, Ozsunar Y, Henson JW, et al. Glial tumor grading and outcome prediction using dynamic spin-echo MR susceptibility mapping compared with conventional contrast-enhanced MR: confounding effect of elevated rCBV of oligodendrogliomas [corrected]. AJNR Am J Neuroradiol 2004;25:214-21 Medline

27. Aronen HJ, Gazit IE, Louis DN, et al. Cerebral blood volume maps of gliomas: comparison with tumor grade and histologic findings. $R a-$ diology 1994;191:41-51 CrossRef Medline

28. Schmiedeskamp H, Straka M, Newbould RD, et al. Combined spin- and gradient-echo perfusion-weighted imaging. Magn Reson Med 2012;68:30-40 CrossRef Medline

29. Law M, Young RJ, Babb JS, et al. Gliomas: predicting time to progression or survival with cerebral blood volume measurements at dynamic susceptibility-weighted contrast-enhanced perfusion MR imaging. Radiology 2008;247:490-98 CrossRef Medline

30. Cha S, Lu S, Johnson G, et al. Dynamic susceptibility contrast MR imaging: correlation of signal intensity changes with cerebral blood volume measurements. J Magn Reson Imaging 2000;11:114-19 CrossRef Medline

31. Harris RJ, Cloughesy TF, Hardy AJ, et al. MRI perfusion measurements calculated using advanced deconvolution techniques predict survival in recurrent glioblastoma treated with bevacizumab. J Neurooncol 2015;122:497-505 CrossRef Medline

32. Hu LS, Eschbacher JM, Dueck AC, et al. Correlations between perfusion MR imaging cerebral blood volume, microvessel quantification, and clinical outcome using stereotactic analysis in recurrent high-grade glioma. AJNR Am J Neuroradiol 2012;33:69-76 CrossRef Medline

33. Surapaneni K, Kennedy BC, Yanagihara TK, et al. Early cerebral blood volume changes predict progression after convection-enhanced delivery of topotecan for recurrent malignant glioma. World Neurosurg 2015;84:163-72 CrossRef Medline

34. Mangla R, Singh G, Ziegelitz D, et al. Changes in relative cerebral blood volume 1 month after radiation-temozolomide therapy can help predict overall survival in patients with glioblastoma. Radiology 2010;256:575-84 CrossRef Medline

35. Prince MR, Zhang HL, Roditi GH, et al. Risk factors for NSF: a literature review. J Magn Reson Imaging 2009;30:1298-308 CrossRef Medline

36. McDonald RJ, McDonald JS, Kallmes DF, et al. Intracranial gadolinium deposition after contrast-enhanced MR imaging. Radiology 2015;275:772-82 CrossRef Medline

37. Cha S. Perfusion MR imaging: basic principles and clinical applications. Magn Reson Imaging Clin N Am 2003;11:403-13 CrossRef Medline

38. Law M, Cha S, Knopp EA, et al. High-grade gliomas and solitary metastases: differentiation by using perfusion and proton spectroscopic MR imaging. Radiology 2002;222:715-21 CrossRef Medline

39. Law M, Oh S, Babb J, et al. Cerebral blood volume predicts patient outcome better than histopathology in low-grade gliomas using dynamic susceptibility contrast-perfusion MR imaging. In: Proceedings of the Annual Meeting of the American Society of Neuroradiology, Toronto, Ontario, Canada. May 23-27, 2005:488 